\title{
PENERAPAN MODEL WATERFALL PADA SISTEM INFORMASI RAWAT JALAN DENGAN KARTU PASIEN BER-BARCODE STUDI KASUS : PUSKESMAS KENANGA SUNGAILIAT
}

\author{
Yuyi Andrika \\ STMIK ATMA LUHUR Pangkalpinang \\ Program Studi Sistem Informasi STMIK Atma Luhur \\ Jl. Jend. Sudirman Selindung Lama Pangkalpinang Kepulauan Bangka Belitung \\ Email : yuyiandrika@atmaluhur.ac.id
}

\begin{abstract}
Abstrak
Dalammelaksanakan kegiatan pelayanan rawat jalan terhadap masyarakat Puskesmas Kenanga masih menggunakan sistem yang manual sehingga apabila banyak pasien yang mendaftar maka antrian menjadi tidak sesuai aturan dan biasanya dalam melakukan pencarian data pasien dan kartu rekam medik pasien membutuhkan banyak waktu sehingga pelayanan menjadi lambat. Penelitian ini menggunakan metode berorientasi objek dimana diagram diagram yang digunakan untuk pemodelan sistem menggunakan Unified Modelling Languange (UML) sedangkan untuk implementasinya menggunakan bahasa pemograman visual studio 2008. Penelitian ini dilakukan untuk mengatasi permasalahan yang terjadi di puskesmas, maka dibutuhkannya sebuah sistem informasi untuk membantu pekerjaan agar pelayanan dalam rawat jalan menjadi lebih efektif dan efesien. Sehingga tidak lagi terjadinya antrian yang tidak tertib dan dalam pencarian kartu rekam medik sangat mudah dilakukan karena di kartu pasien yang berbarcode di sertakan nomor kartu rekam medik sebagai identifikasi pasiennya serta terkontrolnya semua pelayanan rawat jalan karena semua sistem informasi rawat jalan akan terkoneksi dengan menggunakan Local Area Network (LAN).
\end{abstract}

Kata kunci : Puskesmas Kenanga,Sistem Informasi Rawat Jalan, Barcode.

\begin{abstract}
In carrying out activity of outpatient service to community Puskesmas Kenanga still use manual system so that if many patient register then queue become not according to rule and usually in conducting patient data search and medical record card of patient need a lot of time so that service become slow. This study uses object-oriented method where diagrams used for modeling the system using Unified Modeling Languange (UML) while for its implementation using visual studio programming language 2008. This research was conducted to overcome the problems that occur in puskesmas, it needs an information system to help Work for outpatient services to be more effective and efficient. So that no longer the occurrence of the queue is not orderly and in the search for medical record card is very easy to do because the patient card berbarcode in include medical record card number as the identification of patients and controlled all outpatient services because all outpatient information system will be connected by using Local Area Network (LAN).
\end{abstract}

Keywords: Puskesmas Kenanga, Information System Outpatient, Barcode. 


\section{PENDAHULUAN}

Rawat Jalan merupakan salah satu kegiatan yang sangat penting di lembaga kesehatan. Kegiatan ini terjadi setiap hari di Puskesmas Kenanga. Peran Puskesmas Kenanga sangatlah penting dan dibutuhkan oleh masyarakat. Pada Puskesmas Kenanga sendiri berusaha untuk lebih meningkatkan pelayanan kepada masyarakat. Pelayanan rawat jalan pada puskesmas terkendala dengan pendaftaran yang membutuhkan waktu yang lama sehingga antrian menjadi lebih panjang, kartu rekam medik pun sulit dicari karena didata dari nama pasien yang bisa jadi namanya sama dan laporan yang isinya sering salah karena hanya berupa rekapan. Oleh karena itu diperlukan Sistem Informasi Rawat Jalan yag menggunakan barcode untuk mengidentifikasi pasien agar pendaftaran dapat cepat dilakuakan dan pencarian rekam medik sangat mudah serta laporan isinya akan lebih akurat karena tidak lagi berupa laporan. Agar dapat membantu jalannya proses rawat jalan yang ada di Puskesmas Kenanga dan perlu juga didukung oleh sumber daya manusia yang dapat mengelola dan menangani serta memeliharanya.

\subsection{Identifikasi Masalah}

Masalah - masalah yang terjadi pada Puskesmas Kenanga antara lain :

1. Pendaftaran pasien masih dilakukan secara manual.

2. Pencarian kartu rekam medik masih membuthkan waktu yang cukup lama.

3. Pembuatan laporan rawat jalan masih dilakukan secara manual.

4. Laporan jumlah pasien dan laporan pemakaian obat serta permintaan obat dijadikan satu sehingga bingung untuk melihat informasi sesuai kebutuhannya.

\subsection{Tinjauan Pustaka}

Menurut Tata Sutabri dalam bukunya (2012 : 10) "Secara sederhana sistem apat diartikan sebagai suatu kumpulan atau himpunan dari unsur, komponen, atau variabel yang terorganisir, saling berinteraksi, saling tergantung satu sama lain, dan terpadu [1].

Pengertian informasi dijelaskan oleh Tata Sutabri (2012:29), “ Informasi adalah sebuah istilah yang tepat dalam pemakaian umum. Informasi dapat mengenai data mentah, data tersusun, kapasitas sebuah saluran komunikasi dan lain sebagainya. "Informasi merupakan proses lebih lanjut dari data yang sudah memiliki nilai tambah. Informasi adalah data yang telah diklasifikasikan atau diintepretasi untuk digunakan dalam proses pengambilan keputusan. Menurut Tata Sutabri informasi dikelompokkan menjadi tiga bagian, yaitu :

1. Informasi strategis

Informasi ini digunakan untuk mengambil keputusan jangka panjang, yang mencakup informasi eksternal, rencana perluasan perusahaan dan sebagainya.

2. Informasi taktis Informasi ini dibutuhkan untuk mengambil keputusan jangka menengah, seperti informasi trend penjualan yang dapat dimanfaatkan untuk menyusun rencana penjualan.

3. Informasi teknis Informasi ini dibutuhkan untuk keperluan opersaional sehari-hari, seperti informasi persediaan stik, retur penjualan, dan laporan khas harian.

Sistem informasi menurut Tata Sutabri sendiri adalah suatu sistem di dalam organisasi yang mempertemukan kebutuhan pengolahan transaksi harian yang mendukung fungsi operasi organisasi yang bersifat manajerial dengan kegiatan strategi dari suatu organisasi untuk dapat menyediakan kepada pihak luar tertentu dengan laporan - laporan yang diperlukan[1]. 
Unified Modeling Languange (UML) adalah bahasa pemodelan untuk sistem atau perangkat lunak yang berparadigma berorientasi objek. Pemodelan (modelling) sesungguhnya digunakan untuk penyeferhanaan permasalahan - permasalahan yang kompleks sedemikian rupa sehingga lebih mudah dipelajari dan dipahami (Adi Nugroho $2010: 6$ )[2].

Bahasa pemodelan grafis telah ada di industri perangkat lunak sejak lama. Pemicu utama di balik semuanya adalah bahasa pemograman berada pada tingkat abstraksi yang terlalu tinggi untuk memfasilitasi diskusi tentang desain. Dengan menggunakan notasi - notasi seperti UML, alur logika dari perangkat lunak yang akan dikembangkan bisa mudah dipahami. Pemodelan (modelling) sesungguhnya digunakan untuk penyederhanaan permasalahan - permasalahan yang kompleks sedemikian rupa sehingga lebih mudah dipelajari dan dipahami. UML berorientasi objek, menerapkan banyak level abstraksi, tidak bergantung proses pengembangan, tidak bergantung bahasa dan teknologi, pemaduan beberapa notasi diberagam metodologi, usaha bersama dari banyak pihak, didukung oleh berkas - berkas yang diintegrasikan lewat XML. Standar UML dikelola oleh OMG (Object Management Group).

Usecasediagramdigunakan untukmemodelkan bisnis proses berdasarkan perspektif pengguna sistem. Use case diagram terdiri atas diagram untuk use case dan actor. Actor merepresentasikan orang yang akan mengoperasikan atau orang yang berinteraksi dengan sistem aplikasi. Use case merepresentasikan operasi-operasi yang dilakukan oleh actor Use case digambarkan berbentuk elips dengan nama operasi dituliskan didalamnya. Actor yang melakukan operasi dihubungkan dengan garis lurus ke use case.

Menurut Imam Heryanto (2008 : 12), "Entitiy Relationship Diagram merupakan hasil akhir dari proses analisi terhadap sistem yang ditinjau yang dilakukan oleh seorang analis sistem. Yang pertama kali mendeskripsikan diagram ER adalah Peter Chan yang dibuat sebagai bagian dari perangkat lunak case[3].

Sistem Rawat Jalan adalah sub sistem dari sebuah sistem informasi manajemen yang terkoordinasi yang mengolah data medis Pasien Rawat Jalan yang diawali dengan pendaftaran, pencatatan pengorganisasian, pengolahan sehingga menghasilkan laporan yang baik. Sistem Rawat Jalan Puskesmas Sungailiat berfungsi untuk meningkatkan kesehatan masyarakat agar kesehatannya dapat membaik. Tingginya angka kesehatan sangat diperlukan agar tercapainya tujuan pemerintahan daerah. Rendahnya angka kesehatan yang sangat tidak diharapkan pemerintah daerah, bahkan masyarakat luas.

\subsection{Tujuan Penelitian}

Adapun tujuan dari penelitian ini adalah :

1. Pendaftaran bisa diproses dengan cepat tanpa harus antri yang panjang.

2. Pencarian kartu rekam medik dapat dilakukan dengan mudah.

3. Mempemudah dalam pembuatan laporan rawat jalan.

4. Sistem rawat jalan terintegrasi dengan baik.

\section{METODE PENELITIAN}

Metode penelitian yang digunakan adalah metode Waterfall, dimana metode ini merupakan model pengembangan yang terdiri dari tahapan : analisis, perancangan, pengkodean perangkat lunak, dan pengujian. Sehingga kebutuhan Puskesmas Kenanga dapat didefenisikan sesuai dengan kebutuhan pihak yang terlibat. 
Computatio: Journal of Computer Science and Information Systems, volume 1, no 2, Oktober 2017

Dimana pada tahap analisis dilakukan dengan cara menganalisa dokumen yang digunakan di Puskesmas Kenanga dan apa kebutuhan yang diinginkan oleh pihak yang menggunakan sistem dapat diketahui dengan cara wawancara dan observasi.

Tahap perancangan dilakukan dengan cara merancang basisdata kebutuhan data dalam sistem dan merancang Grapichal User Interface (GUI) yang merupakan penghubung antara user dan sistem informasi.

Tahap pengkodean dilakukan dengan cara mendevelopment bahasa pemograman menggunakan visual basic.nett. Setelah pengkodean perangkat lunak dilanjutkan dengan pengujian sistem yang sudah dibuat apakah sudah sesuai antara kebutuhan dan keluaran yang dihasilkan oleh sistem informasi.

\section{HASIL DAN PEMBAHASAN}

\subsection{Perangkat Lunak}

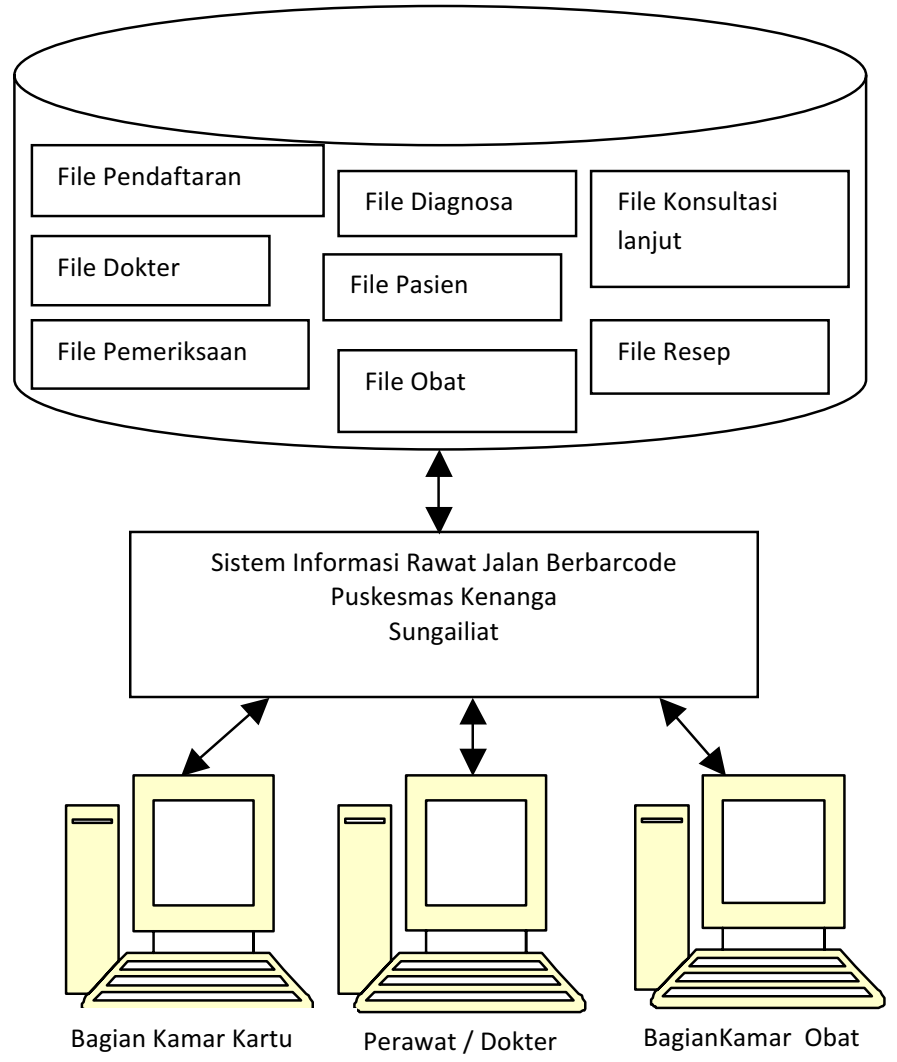

Gambar 1 Perangkat lunak sistem informasi rawat jalan berbarcode Puskesmas Kenanga 


\subsection{Basisdata}

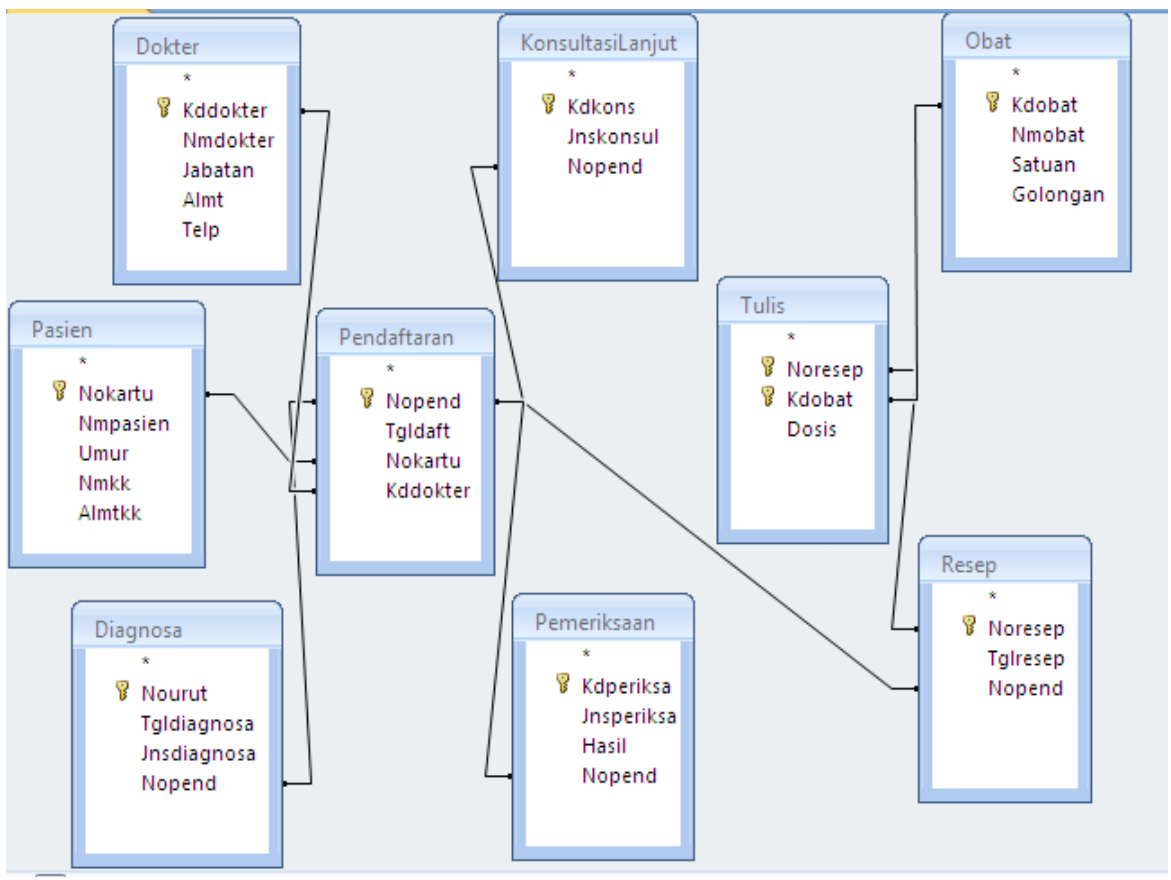

Gambar 2 Basisdata sistem informasi rawat jalan berbarcode Puskesmas Kenanga

\subsection{Flowchart}

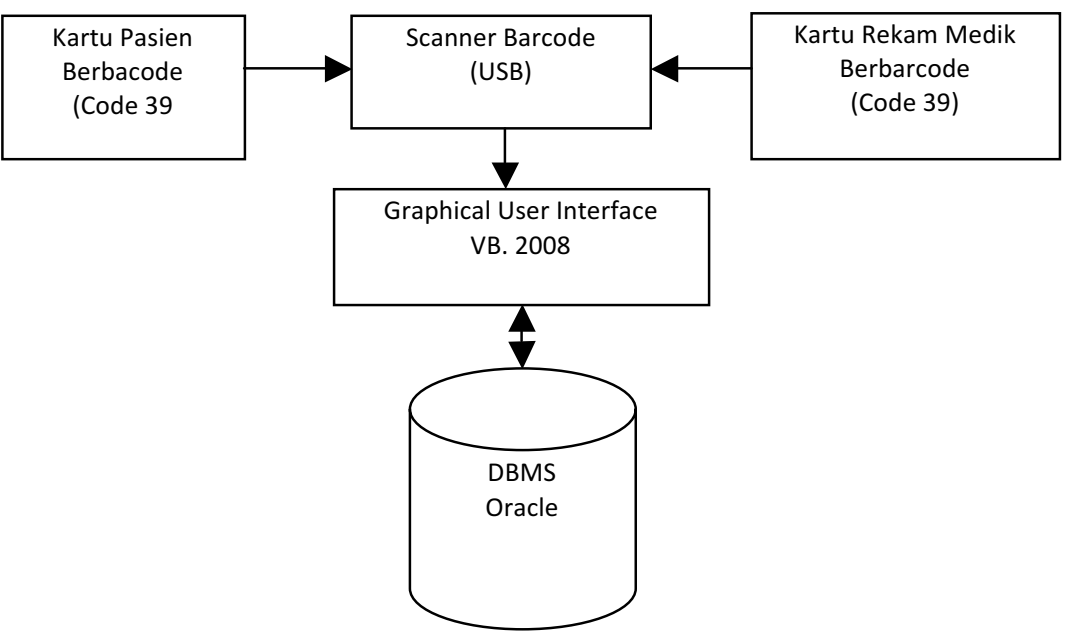

Gambar 3 Flowchart sistem informasi rawat jalan berbarcode Puskesmas Kenanga 
Computatio: Journal of Computer Science and Information Systems, volume 1, no 2, Oktober 2017

2.4 Proses rawat jalan Puskesmas Kenanga
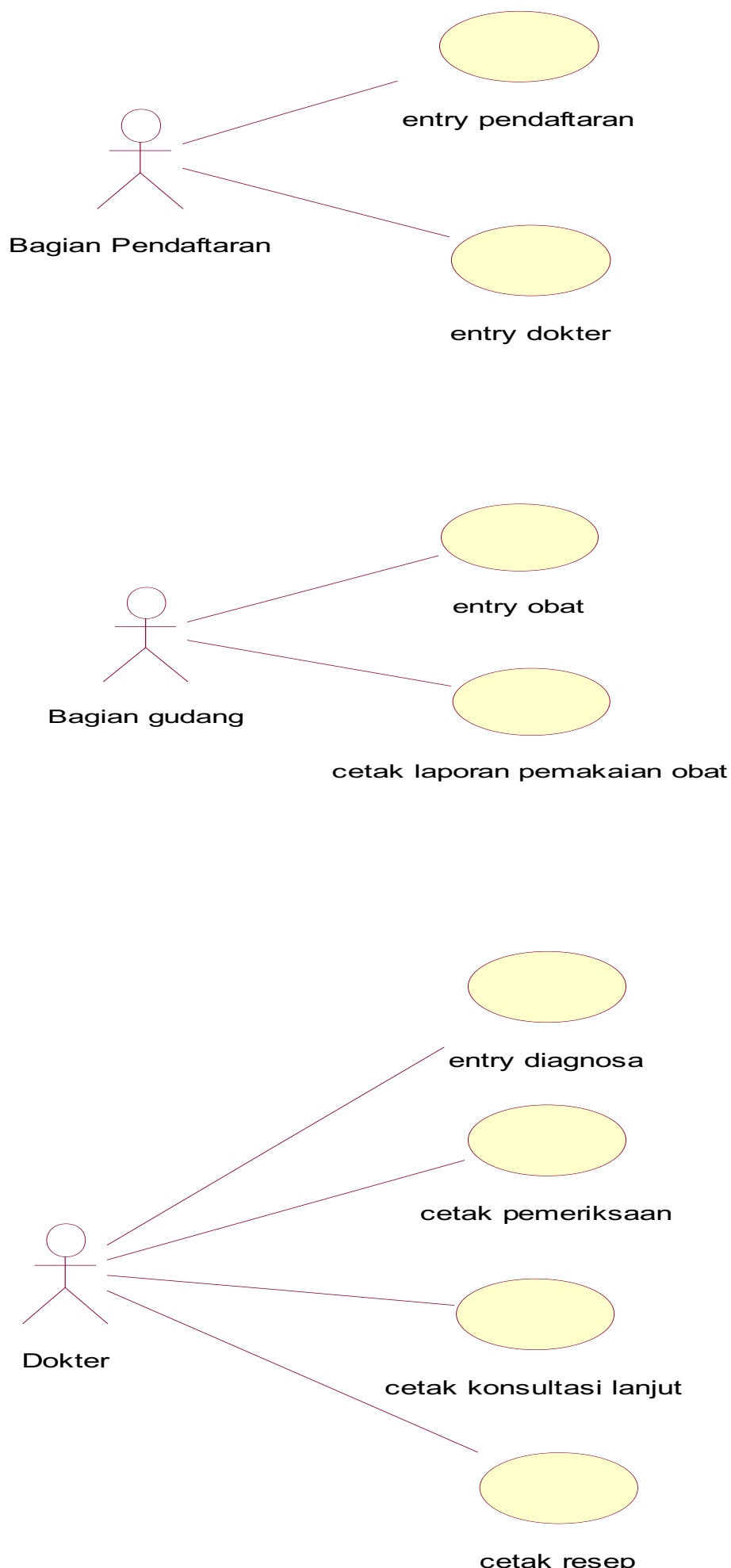

Gambar 4 Proses sistem informasi rawat jalan berbarcode Puskesmas Kenanga 


\subsection{Graphical User Interface (GUI)}

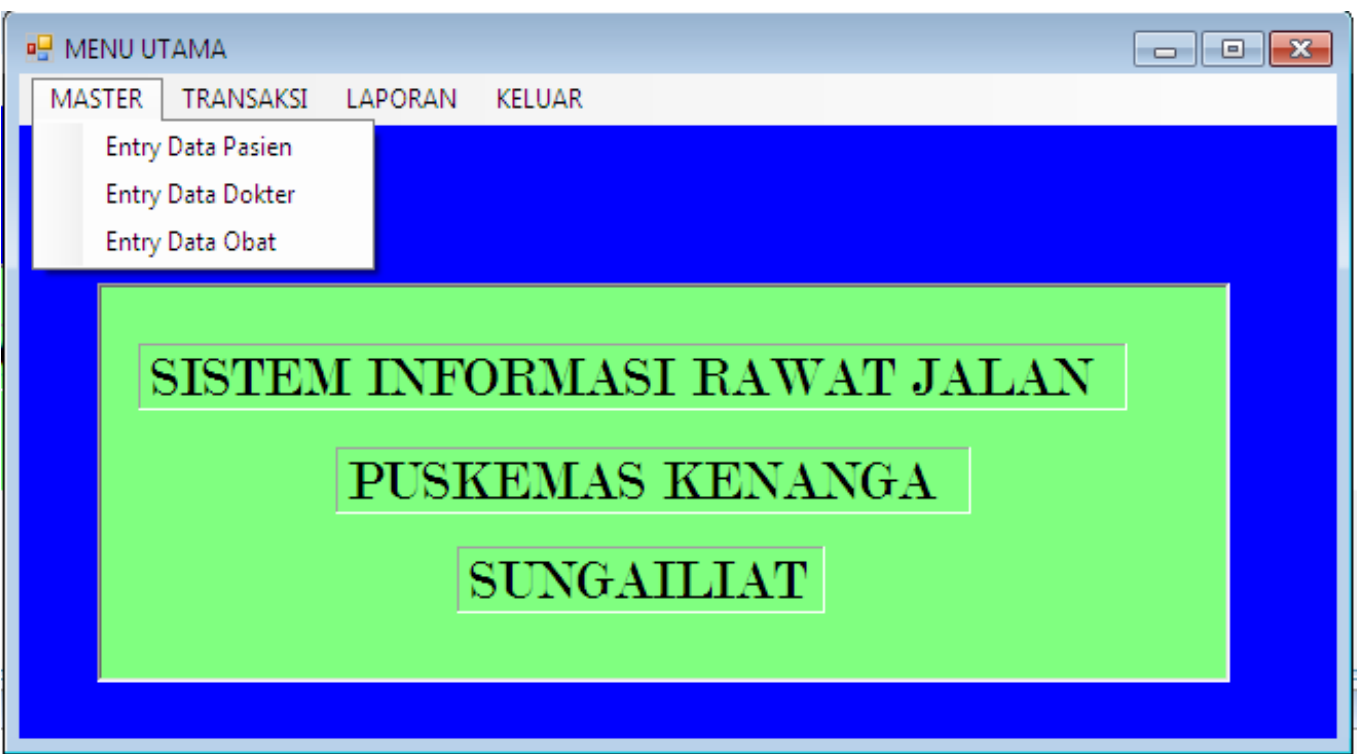

Gambar 5 GUI menu master sistem informasi rawat jalan berbarcode Puskesmas Kenanga

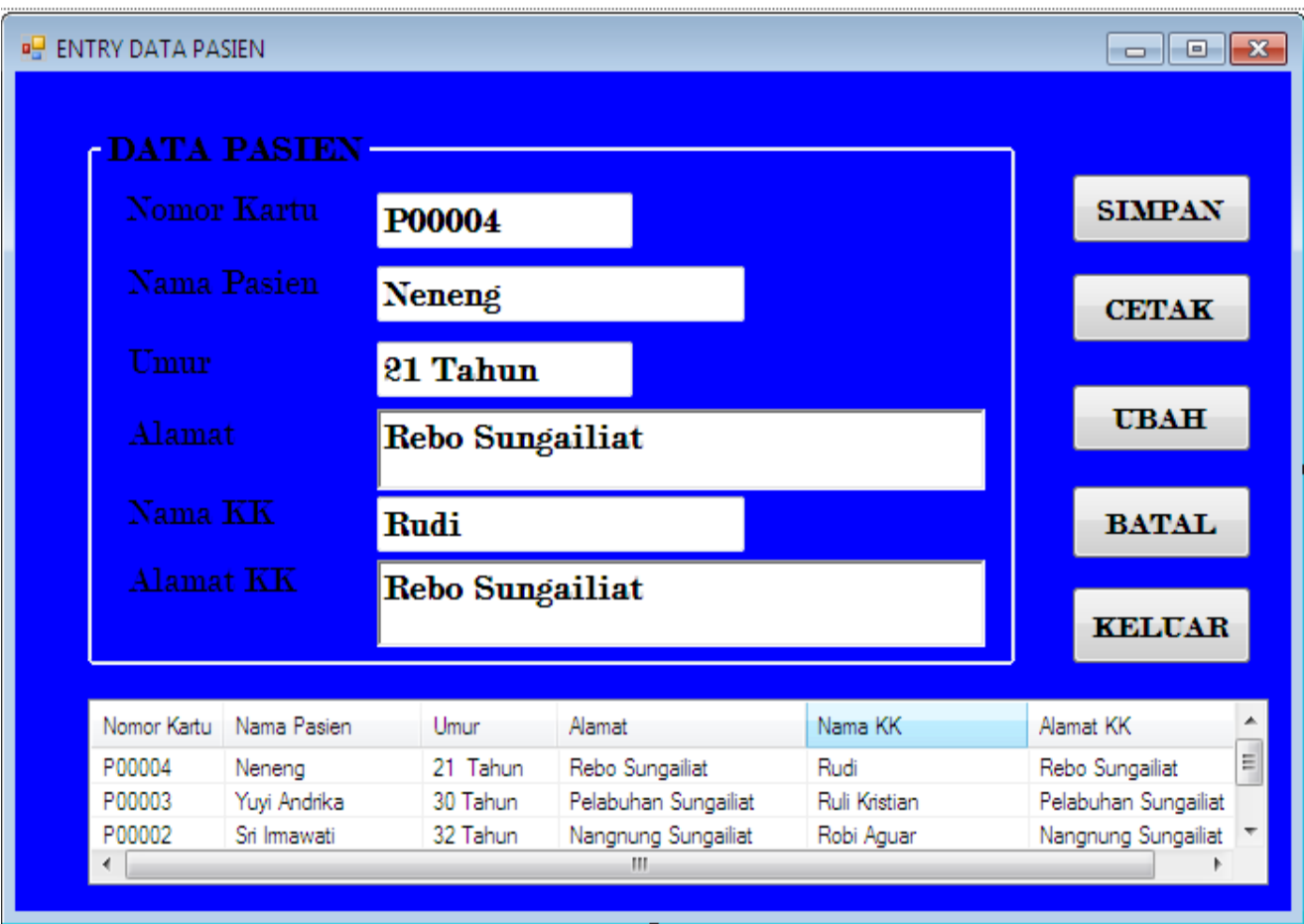

Gambar 6 GUI menu entry data pasien sistem informasi rawat jalan berbarcode Puskesmas Kenanga 
Computatio: Journal of Computer Science and Information Systems, volume 1, no 2, Oktober 2017

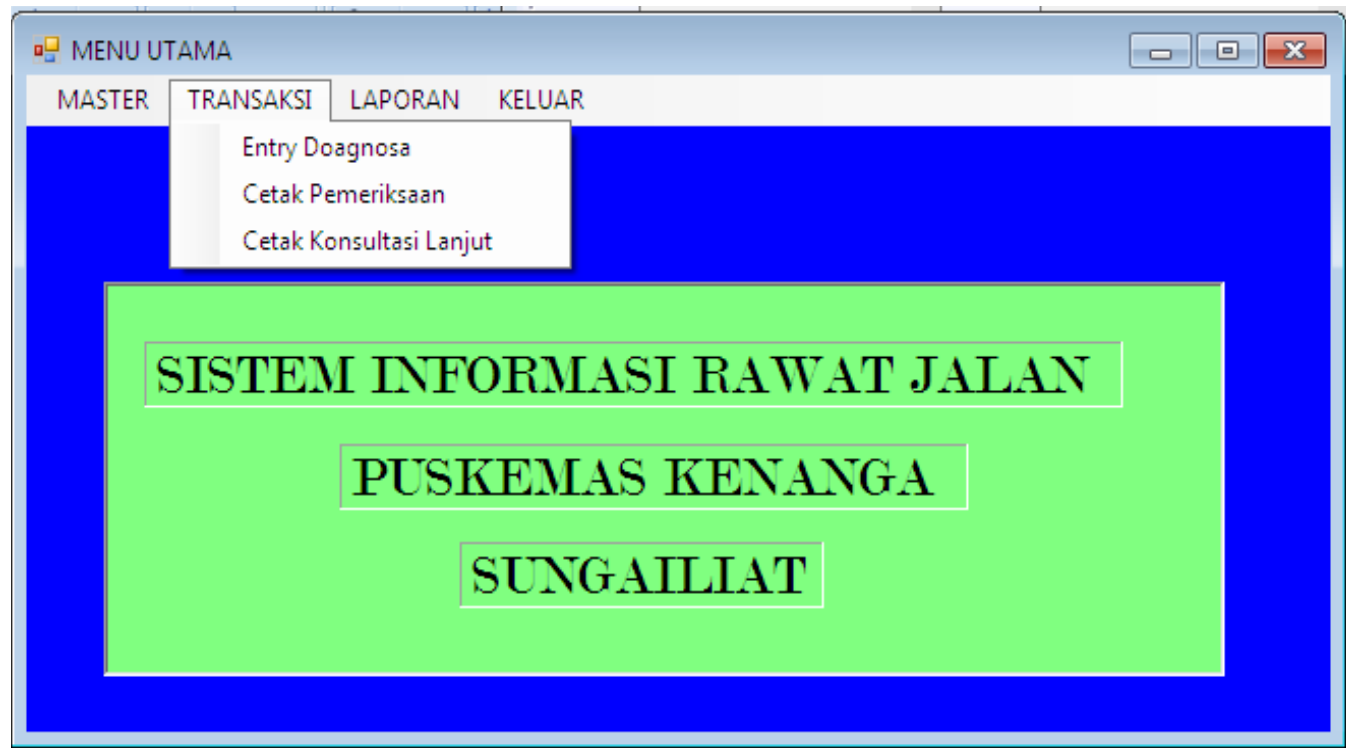

Gambar 7 GUI menu transaksi sistem informasi rawat jalan berbarcode Puskesmas Kenanga

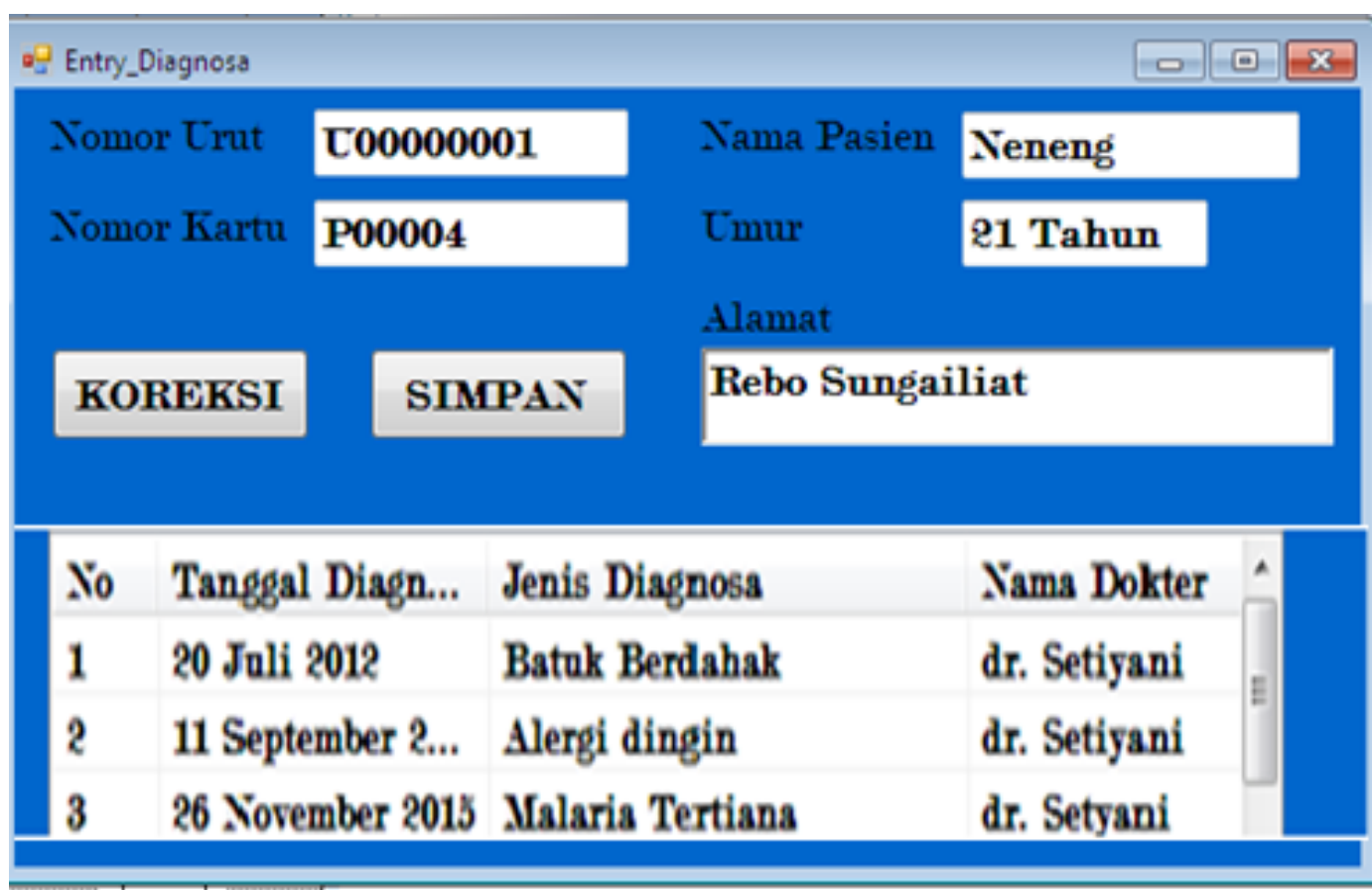

Gambar 8 GUI menu entry diagnosa sistem informasi rawat jalan berbarcode Puskesmas Kenanga

\subsection{Hasil Pengujian}

Pengujian dilakukan dengan menggunakan black box. Dimana pengujian sistem informasi rawat jalan pasien berbarcode pada Puskesmas Kenanga diuji dengan pengentrian yang dilakukan oleh aktor - aktor yang terlibat dalam proses rawat jalan. 
Tabel I Pengujian proses entry data pasien

\begin{tabular}{|c|c|c|c|}
\hline Kebutuhan & Proses Pengujian & Hasil yang diharapkan & Hasil pengujian \\
\hline \multirow[t]{2}{*}{ Simpan pasien } & $\begin{array}{l}\text { Simpan pasien } \\
\text { (jika data benar) }\end{array}$ & $\begin{array}{l}\text { Data akan tersimpan ke } \\
\text { database yaitu ke tabel pasien }\end{array}$ & Sesuai \\
\hline & $\begin{array}{l}\text { Simpan pasien } \\
\text { (jika data salah) }\end{array}$ & $\begin{array}{l}\text { Tampil peringatan untuk } \\
\text { memperbaiki data yang } \\
\text { inputannya salah }\end{array}$ & Sesuai \\
\hline \multirow[t]{2}{*}{ Ubah pasien } & $\begin{array}{l}\text { Ubah data pasien } \\
\text { (jika data benar) }\end{array}$ & $\begin{array}{l}\text { Field yang diubah datanya } \\
\text { akan berubah dan tersimpan di } \\
\text { tabel pasien }\end{array}$ & Sesuai \\
\hline & $\begin{array}{l}\text { Ubah data pasien } \\
\text { (jika data salah) }\end{array}$ & $\begin{array}{l}\text { Field yang diubah datanya } \\
\text { tidak akan berubah dan akan } \\
\text { memunculkan konfirmasi } \\
\text { kesalahan }\end{array}$ & Sesuai \\
\hline \multirow[t]{2}{*}{ Hapus pasien } & $\begin{array}{l}\text { Hapus data (jika } \\
\text { data benar) }\end{array}$ & $\begin{array}{l}\text { Data akan terhapus ke database } \\
\text { yaitu ke tabel pasien }\end{array}$ & Sesuai \\
\hline & $\begin{array}{l}\text { Hapus data (jika } \\
\text { data salah) }\end{array}$ & $\begin{array}{l}\text { Data akan terhapus dari } \\
\text { database yaitu dari tabel pasien }\end{array}$ & Sesuai \\
\hline Cetak Pasien & $\begin{array}{l}\text { Hubungkan ke } \\
\text { printer }\end{array}$ & $\begin{array}{l}\text { Data pasien akan tercetak di } \\
\text { kartu pasien yang memiliki } \\
\text { barcode }\end{array}$ & Sesuai \\
\hline
\end{tabular}

Tabel II Pengujian proses entry diagnosa

\begin{tabular}{|c|c|l|l|}
\hline Kebutuhan & $\begin{array}{c}\text { Proses } \\
\text { Pengujian }\end{array}$ & Hasil yang diharapkan & Hasil pengujian \\
\hline Koreksi diagnosa & $\begin{array}{c}\text { Entry diagnosa } \\
\text { sesuai kunjungan }\end{array}$ & $\begin{array}{l}\text { Diagnosa pasien terentry di } \\
\text { form diagnosa }\end{array}$ & Sesuai \\
\hline Simpan diagnosa & $\begin{array}{c}\text { Simpan data } \\
\text { diagnosa pasien } \\
\text { jika data benar }\end{array}$ & $\begin{array}{l}\text { Data diagnosa akan } \\
\text { tersimpan di tabel diagnosa }\end{array}$ & Sesuai \\
\cline { 2 - 4 } & $\begin{array}{c}\text { Simpan data } \\
\text { diagnosa pasien } \\
\text { jika salah }\end{array}$ & $\begin{array}{l}\text { Akan muncul pesan cek } \\
\text { lagi diagnosa sudah sesuai } \\
\text { apa belum }\end{array}$ & Sesuai \\
\hline
\end{tabular}

2.6 Hasil cetakan kartu pasien berbarcode

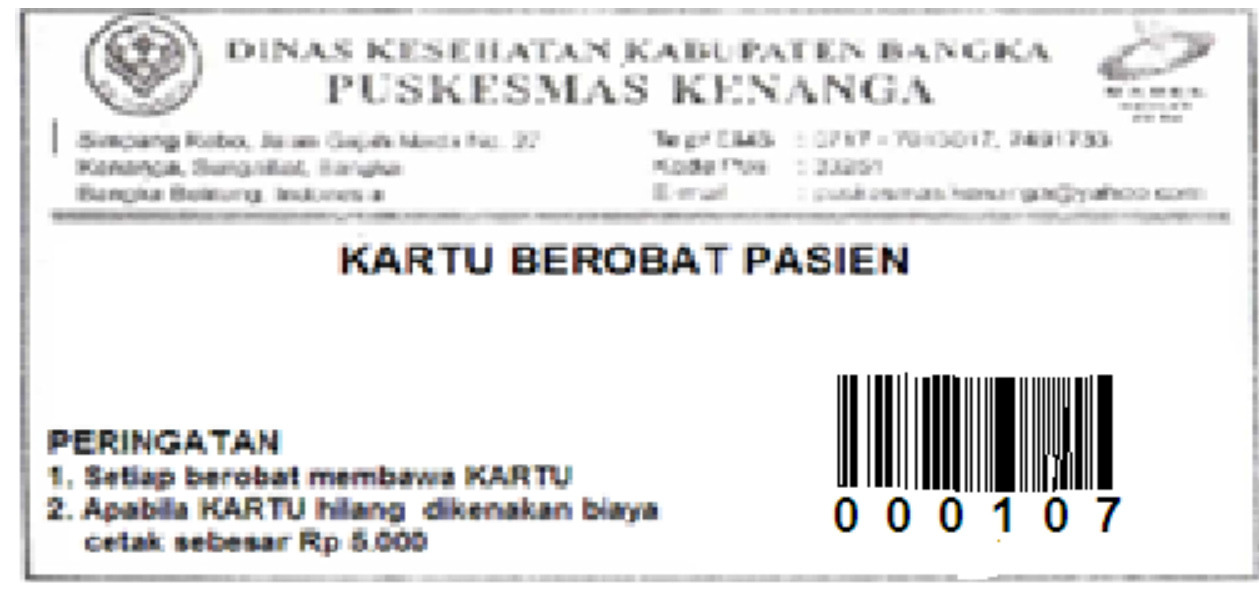

Gambar 9 Kartu pasien berbarcode 


\section{KESIMPULAN}

1. Dengan adanya penerapan sistem informasi rawat jalan dengan kartu berbarcode maka pendaftaran dapat dilakukan dengan cepat tanpa harus melakukan pencatatan di buku lagi untuk data pasien dan kunjungan pasiennya.

2. Sistem informasi dapat mempermudah melakukan pencarian kartu rekam medik hanya dengan melakukan scan terhadap kartu pasiennya saja.

3. Laporan dapat dicetak kapan waktu sesuai dengan kebutuhan dengan menggunakan periode yang dibutuhkan.

4. Apabila terjadi kesalah maka dapat dicek siapa yang melakukan kesalahan karena sistem menggunakan sistem user login dan sudah terintegrasi dengan baik.

\section{DAFTAR PUSTAKA}

[1] Sutabri, Tata, 2012,Analisis Sistem Informasi, Yogyakarta : Andi.

[2] Nugroho, Adi, 2010, Rekayasa Perangkat Lunak Menggunakan UML dan Java, Edisi 1, Andi Publisher, 2010.

[3] Haryanto, Imam, 2008, Membuat Database dengan Microsoft Access, Informatika Bandung: Bandung.

[4] Fadlil Abdul, 2008, Pengembangan Sistem Basis Data Presensi Perkuliahan Dengan Kartu Mahasiswa Ber-Barcode, Yogyakarta, 1 April 2008.

[5] Pressman, R.S, 2002, Rekayasa Perangkat Lunak Pendekatan Praktisi (buku Dua), Yogyakarta, Andi. 